\title{
ARMAZENAMENTO DE GRÃOS EM PEQUEQUENAS PROPRIEDADES DE SÃO FRANCISCO, PARAÍBA, BRASIL
}

\author{
Marília Hortência Batista Silva Rodrigues ${ }^{1}$, Valéria Fernandes de Oliveira Sousa ${ }^{1}$, Gisele Lopes dos Santos ${ }^{1}$, \\ Everson Pedrosa de Nobrega², Francisco Edu de Andrade ${ }^{2}$ \\ ${ }^{1}$ Universidade Federal de Campina Grande - UFCG, Programa de Pós Graduação em Horticultura Tropical, Pombal, PB. \\ ${ }^{2}$ Instituto Federal da Paraíba - IFPB, PB. E-mail: marilia agroecologa@hotmail.com
}

\section{RESUMO}

O armazenamento de grãos é uma prática relevante na região Nordeste, praticada principalmente pelos agricultores familiares. Porém, a estocagem inadequada acarreta em perdas deste material. Logo, objetivou-se diagnosticar as técnicas utilizadas para o armazenamento de grãos em pequenas propriedades rurais do município de São Francisco, Paraíba. A pesquisa foi realizada em 50 propriedades produtoras, pertencentes a comunidades rurais (Santo Amaro e Ramada), no período compreendido entre os meses de janeiro a fevereiro de 2018. Para isto, foram utilizadas como recurso metodológico, entrevistas semi-estruturadas in loco, que consistiam no preenchimento de um formulário com 14 questões, sendo três sobre o perfil dos entrevistados e as demais sobre as culturas produzidas e tipo de armazenamento empregado. Constatou-se que o tipo de recipiente para armazenamento de grãos mais utilizado é o de garrafas plásticas. No entanto, os produtores rurais do município de São Francisco-PB possuem pouco conhecimento relacionado as técnicas de armazenagem, apresentando ainda perdas significativas de grãos durante o processo de armazenamento.

Palavras-chave: agricultura familiar; estocagem; sertão paraibano.

\section{STORAGE OF GRAINS IN SMALL PROPERTIES OF SÃO FRANCISCO, PARAÍBA, BRAZIL}

\begin{abstract}
Grain storage is a relevant practice in the region Northeast, practiced mainly by family farmers. But, inadequate storage leads to losses of this material. Therefore, the objective was to diagnose the techniques used for grain storage in small rural properties in the municipality of São Francisco, Paraíba. The research was carried out in 50 producing properties, belonging to rural communities (Santo Amaro and Ramada), in the period understood between January and February of 2018. For this, were used as methodological resource, semi-structured interviews in loco, which consisted in completing a form with 14 questions, three being about the profile of the interviewees and the others about the crops produced and the type of storage employed. It has been found that the type of container for grain storage most used is that of plastic bottles. However, the rural producers in the municipality of São Francisco-PB have little knowledge related to storage techniques, with significant grain losses during the storage process.
\end{abstract}

Keywords: family agriculture; storage; sertão paraibano.

\section{INTRODUÇÃO}

O Brasil vem apresentando grande destaque no comércio internacional como exportador de produtos agrícolas, principalmente pela alta produção de grãos. Na safra de 2016/2017 foram colhidos nacionalmente 238,7 milhões de toneladas (CONAB, 2017). Contudo, parte desta produção é armazenada, e o país além de enfrentar problemas decorrentes da capacidade estática limitada é estimado que aproximadamente $20 \%$ da produção anual de grãos seja perdida devido a inadequada estocagem dos mesmos (CAMPOS, 2008; MAIA et al., 2013).

$\mathrm{Na}$ região Nordeste a prática de estocagem de grãos ou sementes é bastante comum, como é o caso de pequenos agricultores do sertão paraibano nas suas propriedades. Isto 
ocorre devido a vários fatores aos quais: preço desvalorizado do produto no momento da colheita pelo excesso de oferta, necessidade de guardar parte da produção para o consumo da família (levando em consideração que são agricultores familiares e que praticam a agricultura de subsistência) e estocagem para utilização em novas safras.

Desta forma, os produtores acabam preservando e valorizando as sementes crioulas, sendo esta uma prática importante de convívio com o semiárido, gerando também mais autonomia ao agricultor, na medida em que lhe permite plantar no tempo que lhe convém e com a vantagem de apresentar igual ou maior resistência quando comparadas às sementes transgênicas (TEIXEIRA; PIRES, 2017).

Entretanto, grãos ou sementes estão susceptíveis a redução da qualidade fisiológica durante a permanência na unidade armazenadora independente da espécie. Cardoso et al. (2012), afirmam que o processo de deterioração é de certa forma inevitável, porém, pode ser retardado conforme as condições de armazenamento e características do produto.

De acordo com Pimentel et al. (2011) a intervenção por meio de práticas que minimizem perdas em todas as escalas de produção, seja por pequenos, médios e grandes produtores, objetivam além de assegurar a qualidade final do produto, a garantia de saúde e segurança nutricional de produtores e consumidores. Dentre estas práticas, destacam-se o controle da temperatura e umidade, não devendo ultrapassar os $25{ }^{\circ} \mathrm{C}$ e os $70 \%$, respectivamente, e a manutenção e limpeza do local de armazenagem para evitar o ataque de pragas, fungos ou roedores (LORINI et al., 2015).

A falta de investimentos para construção de unidades armazenadoras e de capacitação quanto ao armazenamento adequado para pequenos agricultores, também são determinantes quanto perdas quantitativas e qualitativas. Além disso, poucos trabalhos relatam sobre armazenamento de grãos em comunidades rurais e a sua viabilidade. Nesta perspectiva, objetivou-se diagnosticar as técnicas utilizadas para o armazenamento de grãos em pequenas propriedades rurais do município de São Francisco, Paraíba.

\section{MATERIAL E MÉTODOS}

O estudo foi desenvolvido no sítio Ramada e Santo Amaro localizado na zona rural do município de São Francisco-PB, no período compreendido entre os meses de janeiro a fevereiro de 2018. O município de São Francisco está situado no sertão paraibano, sob as coordenadas geográficas $06^{\circ} 37^{\prime} \mathrm{S}, 38^{\circ} 05^{\prime} \mathrm{W}$ e altitude de $285 \mathrm{~m}$. De acordo com último censo, possui 3.364 habitantes com 2001 residentes na zona rural, ou seja, $59 \%$ da população e índice de desenvolvimento humano 0,58 , considerado baixo (IBGE, 2010).

Para a realização deste trabalho foram utilizadas, como recurso metodológico, as entrevistas semi-estruturadas in loco, que consistem em um roteiro contendo uma lista de questões e tópicos a serem abordados em 50 propriedades produtoras, pertencentes a comunidades rurais (Santo Amaro e Ramada) conforme observa-se na Figura 1.

Figura 1. Localização da área estudada (Santo Amaro e Ramada) pertencente ao município de São Francisco, Paraíba, 2018.
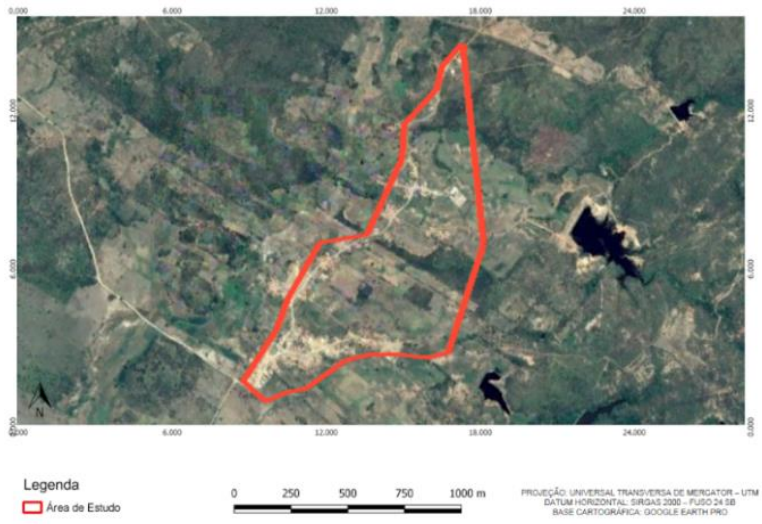

O formulário era composto por 14 questões, das quais três eram voltadas para caracterização do perfil dos entrevistados como: idade, escolaridade e características familiares, e 
as demais sobre quais os tipos de culturas produzidas e as estratégias empregadas quanto o armazenamento de grãos.

A metodologia utilizada para determinação do número de indivíduos entrevistados foi a de Levin (1987), tomando como base a estimativa populacional. Os procedimentos empregados para determinação da equação matemática que permitiu o cálculo da amostra (n) a partir da estimativa da proporção populacional foram determinados pelos seguintes critérios: $a$. Populações finitas; b. Grau de confiança 95\%; c. Nível de significância $\alpha$ de 0,05. Para isto, utilizou-se a seguinte equação:

$$
n=\frac{N \cdot p \cdot q \cdot\left(\frac{Z a}{2}\right)^{2}}{p \cdot q \cdot\left(\frac{Z a}{2}\right)^{2}+(N-1) \cdot E^{2}}
$$

em que:

n é a quantidade de indivíduos que se pretende calcular; $N$ é o tamanho da população; $Z \alpha / 2$ é o valor crítico que corresponde o grau de confiança desejado; $p^{\wedge}$ é a proporção populacional de indivíduos que pertencem à categoria de interesse no estudo $=0,5 ; q^{\wedge}$ corresponde $a$ quantidade de indivíduos que não participa do grupo pesquisado $(q=1-p)=0,5$. Deste modo, como $p^{\wedge}$ era desconhecido fez a relação do produto $p^{\wedge} \cdot q^{\wedge}=0,25$, que é o maior valor que pode ser alcançado por essa relação $p^{\wedge} . q^{\wedge}$ (LEVINE, 2000). E é a Margem de erro.

Os dados foram tabulados em planilhas eletrônica do Microsoft Excel e os gráficos foram plotados por meio do programa SigmaPlot versão 10.0.

\section{RESULTADOS E DISCUSSÃO}

De acordo com os resultados obtidos a partir dos agricultores entrevistados, contatou-se que $62 \%$ destes eram do gênero masculino e $38 \%$ do gênero feminino. Quanto a faixa etária $22 \%$ estão na faixa etária de 21 a 40 anos, $42 \%$ de 41 a 60 anos e $36 \%$ acima dos 60 anos. Em relação ao nível de escolaridade, foi observado que $26 \%$ dos agricultores possuem o fundamental completo, $56 \%$ fundamental incompleto e $18 \%$ não possuem formação.

A escolaridade é um indicador preciso do nível socioeconômico de uma população por estar relacionado às possibilidades de acesso a empregos, renda, à receptividade aos programas educacionais e sanitários, e a falta de formação principalmente aos adultos e idosos oriundos da zona rural está atrelada a necessidade de trabalhar precocemente, muita das vezes no trabalho árduo do campo (LLANO et al., 2017).

Dentre os principais grãos armazenados nestas pequenas propriedades, foram destacados o milho e o feijão, ambos com totalidade, isto é, os 50 produtores rurais entrevistados (Figura 2). Essas culturas possuem grande relevância para a Região Nordeste, sendo, o armazenamento destes grãos uma prática oriunda de geração para geração entre os pequenos agricultores à espera do período chuvoso, que geralmente ocorre de janeiro a abril, para o cultivo dos mesmos.

Figura 2. Principais grãos armazenados na Zona Rural (Santo Amaro e Ramada) de São Francisco, Paraíba, 2018.

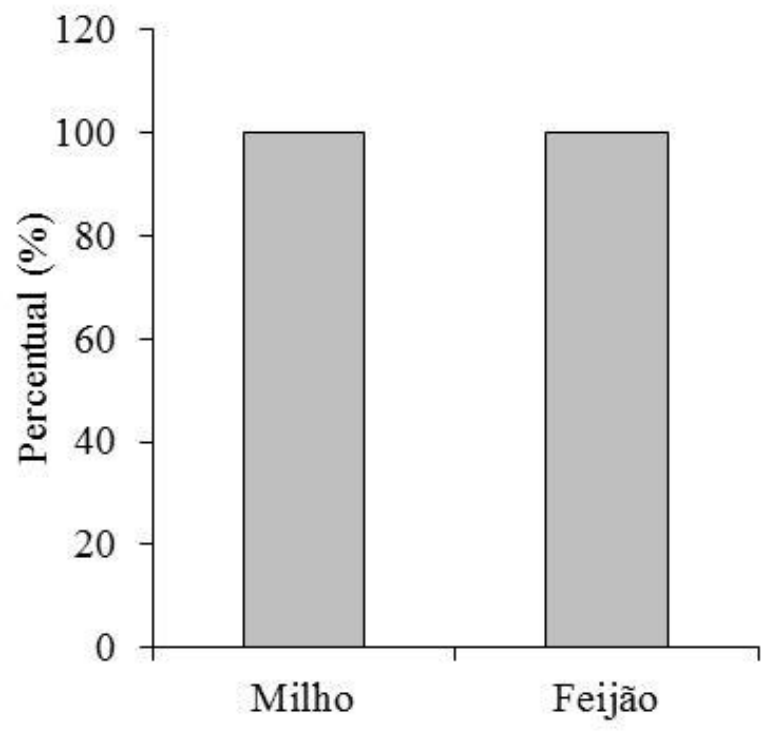


A economia do semiárido paraibano baseia-se na agricultura e pecuária, tendo como os principais produtos agrícolas, no sistema de sequeiro, o milho, feijão e mandioca, enquanto que na pecuária, destaca-se criação de bovinos, caprinos e ovinos, os quais necessitam do milho para alimentação dos animais (MARREIROS et al., 2015). Assim, a armazenagem desses produtos é importante para a agricultura de subsistência.

Os produtores rurais de Santo Amaro e Ramada afirmaram possuir armazenamento adequado para o acondicionamento dos grãos, sendo os mais utilizados as garrafas plásticas com 44 dos entrevistados e silos metálicos equivalente a 6 produtores, conforme observase na Figura 3. O processo de deterioração das sementes é influenciado pelo tipo de embalagem utilizada para o acondicionamento, levando em consideração que a semente é higroscópica, o tipo de embalagem pode favorecer ou não a troca de vapor d'água entre a semente e o ambiente (MARCOS FILHO, 2015). Portanto, as garrafas plásticas são consideradas adequadas para o armazenamento, devido serem recipientes herméticos que dificultam essa troca de vapor d'água, retardando desta forma o processo de deterioração e garantindo maior longevidade e qualidade nutricional.

Figura 3. Tipos de recipientes usados para o armazenamento de grãos na Zona Rural (Santo Amaro e Ramada) de São Francisco, Paraíba, 2018.

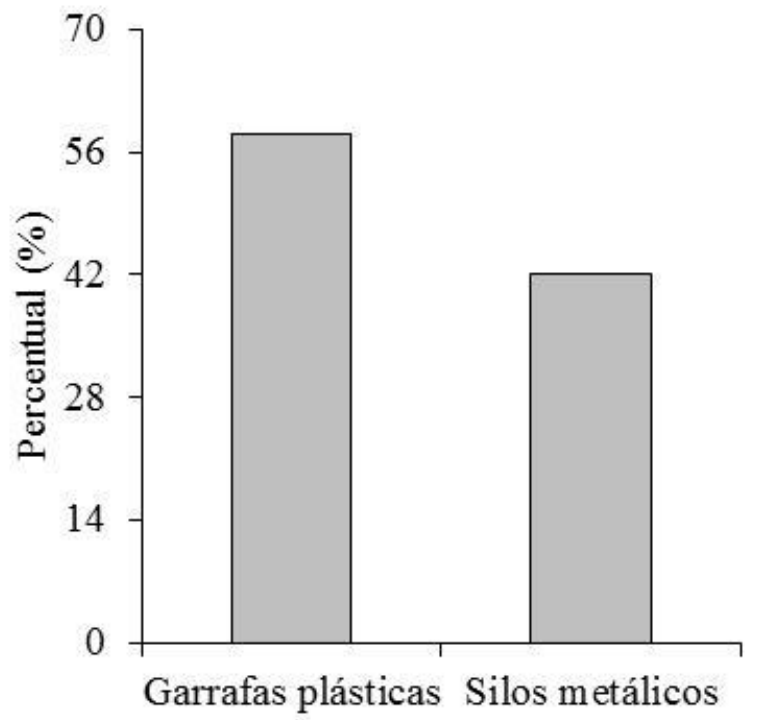

Resultados corroboram com Sousa Júnior et al. (2011), os quais destacam que a maioria dos agricultores oriundos do município de Pombal-PB fazem uso de garrafas PET para 0 armazenamento de grãos destinados ao consumo, correspondendo a 95\%, diante a praticidade e a falta de instalações físicas adequadas para armazenamento. $O$ que nos remete que o emprego deste recipiente acaba se tornando uma alternativa viável na agricultura familiar, por ser mais acessível e um tanto eficiente, apresentando menores custos e perdas.

O armazenamento em silo metálico também não deixa de ser eficiente, desde que seja corretamente isento de resíduos em seu interior e que haja a sua correta vedação. Este é preferencialmente usado por agricultores que produzem grãos não apenas para o próprio consumo, mas também para comercialização, principalmente para disponibilidade dos grãos durante o período de entressafra, que faz com que os mesmos apresentem maior valor econômico e consequentemente maior rentabilidade ao produtor (FUJII et al., 2015).

Corroborando com os recipientes utilizados, ao se questionar a finalidade do armazenamento de grãos aos produtores destas pequenas propriedades rurais (Figura 4), os mesmos destacaram que a principal é a de consumo, com superioridade de $28 \%$, e parte excedente é usada para a comercialização. Este fator é de suma importância, visto que, apontam a agricultura familiar ainda como a base de comunidades rurais. 
Figura 4. Finalidade do armazenamento de grãos na Zona Rural (Santo Amaro e Ramada) de São Francisco, Paraíba, 2018.

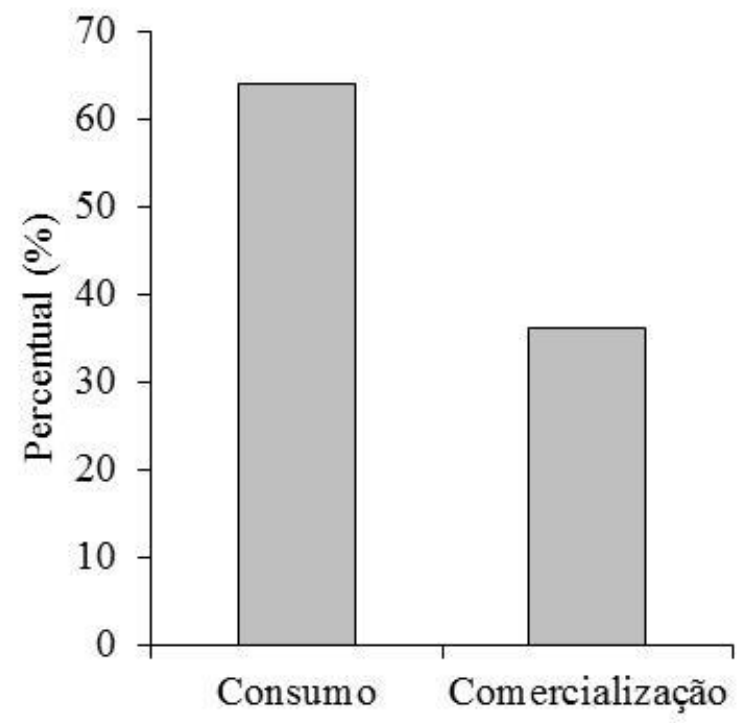

Camargo e Navas (2017), afirmam que a produção de alimentos praticada pelas sociedades rurais sempre esteve fortemente ligada às estratégias de segurança alimentar, principalmente para seu próprio consumo. Porém, atualmente observa-se uma pequena ruptura desse processo, em razão da inserção do modelo de desenvolvimento capitalista na agricultura e pela aproximação dos universos urbano e rural, levando os agricultores a atender o mercado, em substituição às necessidades alimentares da família e ao aumento e diversificação dos níveis de renda, através da priorização em atender os mercados, como também programas nacionais governamentais que visam a compra dos produtos oriundos da agricultura familiar, como por exemplo, Programa de Aquisição de Alimentos (SANTOS et al., 2014).

Com relação aos materiais utilizados para a limpeza dos recipientes para o adequado armazenamento dos grãos, 36 produtores afirmaram fazer a limpeza apenas com água e 14 afirmam usar água e detergente (Figura 5).

Figura 5. Materiais utilizados para a limpeza dos recipientes que são usados para armazenamento de grãos na Zona Rural (Santo Amaro e Ramada) de São Francisco, Paraíba, 2018.

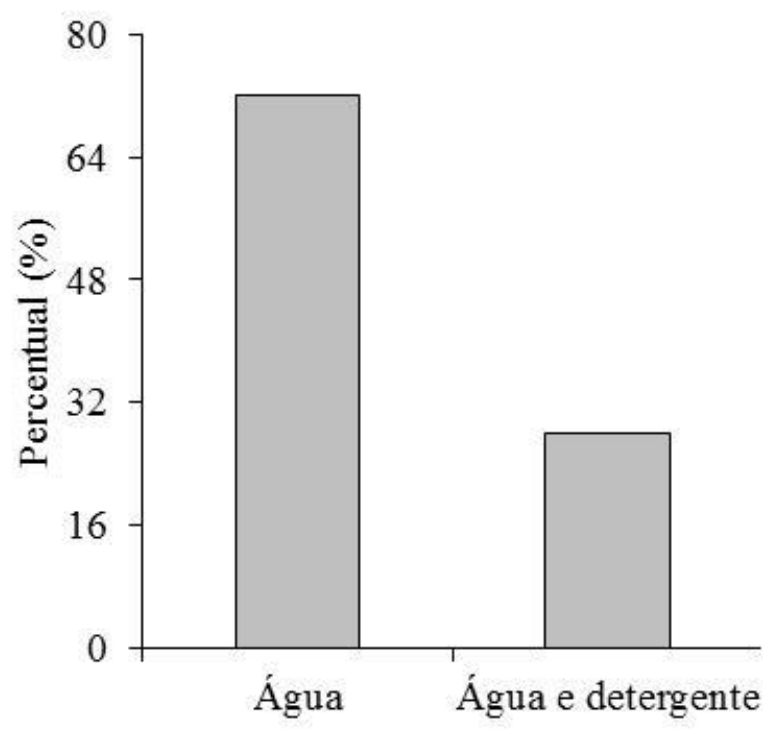

É extremamente importante a limpeza adequada destes recipientes, pois caso contrário estes podem se tornar um veículo de contaminação (insetos, fungos, umidade e restos de sementes das safras passadas). Portanto, a prévia limpeza e higienização das embalagens e 
equipamentos são procedimentos indispensáveis para uma boa conservação das sementes, prevenindo perdas qualiquantitativas, durante $o$ período de armazenamento (ARAÚjo et al., 2012).

Em relação ao tempo de estocagem dos grãos, 9 dos produtores rurais afirmaram que armazenam os mesmos durante seis meses, enquanto que 13 conservam durante um ano e
28 até dois anos (Figura 6). O tempo prolongado de armazenamento pode ser um fator prejudicial para a perca da qualidade dos grãos, pois os fatores abióticos como alta umidade e temperatura, dificultam o armazenamento de sementes por longos períodos nos trópicos, em parte, devido favorecer ao ataque e a proliferação de insetos (CARVALHO, 2016).

Figura 6. Tempo em que os grãos ficam armazenados na Zona Rural (Santo Amaro e Ramada) de São Francisco, Paraíba, 2018.

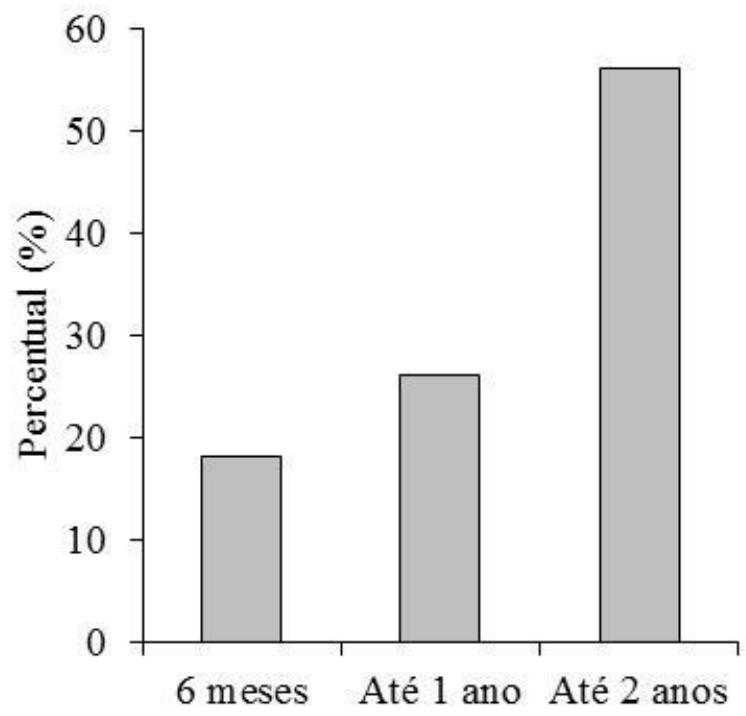

Andrade et al. (2017), ao avaliarem a qualidade do milho segunda safra em função do tempo entre a colheita e a secagem, concluíram que o aumento do teor de umidade na colheita influencia negativamente a qualidade física e sanitária dos grãos, e este efeito é potencializado com o tempo de armazenamento temporário, logo a influência do tempo de armazenamento diminui a viabilidade dos grãos dependendo das condições impostas.

$\mathrm{Na}$ agricultura familiar o uso do grão como semente é totalmente utilizado (Figura 7). A prática de armazenagem de grãos para uso como semente não é algo atual, é uma prática originária de tempos atrás, mas que vem ganhando importância, devido a busca por agricultura livre de agrotóxicos e contra sementes geneticamente modificadas, que não se adaptam ao seu sistema produtivo, com isso agricultores familiares de vários municípios do sertão paraibano têm criado banco de sementes, alguns até se integram a uma rede denominada "Sementes da Paixão" com intuito de preservar as sementes crioulas (PAULINO; GOMES, 2015).

Além disso, muitos pequenos e médios produtores desejam ter sua própria estrutura de armazenamento de grãos para sementes com o objetivo de racionalizar compra de sementes, a espera da próxima safra para o cultivo (VERGARA et al., 2017). 
Figura 7. Uso dos grãos como semente na Zona Rural (Santo Amaro e Ramada) de São Francisco, Paraíba, 2018.

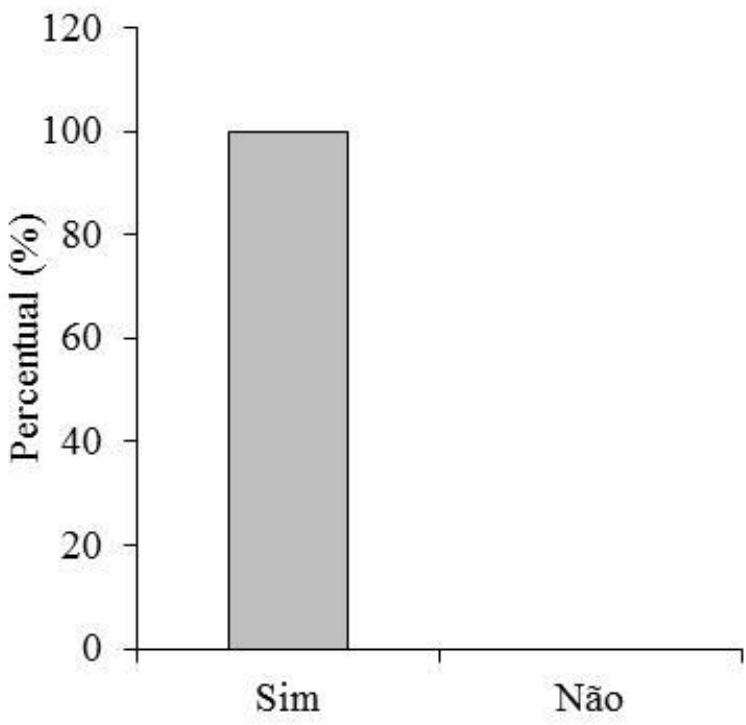

Porém, como a principal finalidade do armazenamento de grãos é utilizá-lo como semente no período da safra, os produtores necessitam se atentar para o período de armazenamento, Cassol et al. (2016), ao analisarem a fisiologia de sementes e grãos de feijão durante o armazenamento, observaram que o período de armazenamento de 360 dias em condições naturais afetou o comportamento fisiológico de sementes e grãos testados.

Muitos produtores se preocupam apenas com a higienização dos grãos, sendo que, no processo de armazenamento também é relevante a limpeza adequada da unidade armazenadora, no referido levantamento 17 dos agricultores se preocupam, sendo que a maioria (33) não possuem esse cuidado ao realizar a estocagem dos grãos (Figura 8). Alguns agricultores citaram ainda que armazenam os grãos junto a outros insumos usados na propriedade como ferramentas e inseticidas. É extremamente importante que o armazém seja construído especificamente para esta finalidade, ou seja, armazenar grãos e sementes, pois fatores como luminosidade, temperatura e umidade podem colocar em risco a qualidade do material vegetal armazenado, bem como a saúde do produtor (LORINI et al., 2015).

Figura 8. Correta limpeza da unidade armazenadora da Zona Rural (Santo Amaro e Ramada) de São Francisco, Paraíba, 2018.

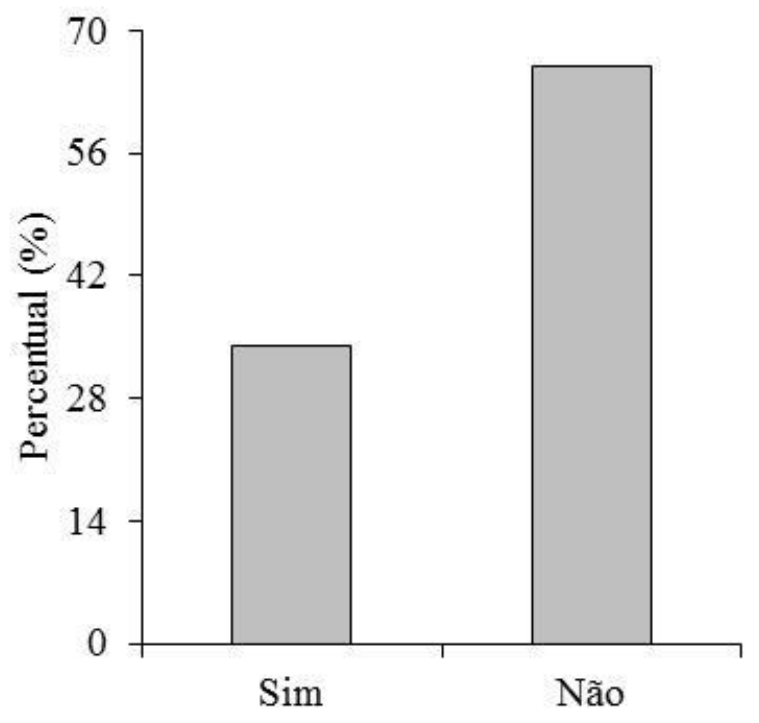


Segundo a Embrapa (2010), faz-se necessário o emprego adequado de medidas de limpeza e higienização da unidade armazenadora, pois, este é o ponto decisivo para o sucesso da meta estabelecida, tornando perceptível que as instalações representam estratégias de ganhos no processo primário, em que a eliminação total dos focos de infestações dentro da unidade como, resíduos de grãos, poeiras, sobras de processo entre outros, favorecem uma melhor condição de armazenamento e viabilidade do produto armazenado.

Em relação ao tratamento de grãos em processo de pré armazenamento, foi possível observar que é comum a pratica de secagem das sementes buscando a redução da umidade, o que possibilita a diminuição de danos mecânicos nos grãos, bem como, minimização de infestantes, cabendo ressaltar que a redução da umidade da semente desacelera o metabolismo e retarda a deterioração (CAIXETA et al., 2014).

Logo, constatou-se que 40 dos agricultores realizam a secagem natural ao sol e 10 fazem pulverização para a eliminação destes infestantes (Figura 9). No entanto, ao serem questionados sobre o perigo destas aplicações de inseticidas os agricultores desconheciam qualquer risco associado ao uso destes produtos químicos.

A secagem natural é o método mais utilizado pelos agricultores para a secagem das sementes, devido ser uma forma simples, prática e de nenhum custo, sendo as sementes secas pela ação do vento e da energia calórica da luz solar e por não exigirem equipamentos sofisticados como os equipamentos elétricos ou eletrônicos que são utilizados nos métodos de secagem artificial (CARVALHO; NAKAGAWA, 2012).

Figura 9. Tratamento de grãos pré armazenamento, na Zona Rural (Santo Amaro e Ramada) de São Francisco, Paraíba, 2018.

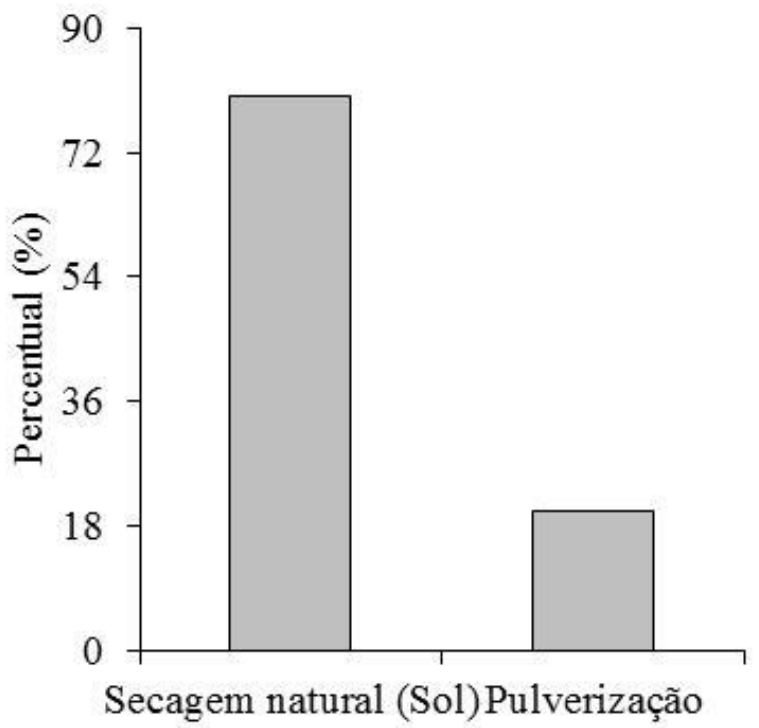

Entre os materiais utilizados para a vedação dos recipientes que armazenam os grãos foram citados por 29 produtores o uso do sabão e 21 a cera de abelha (Figura 10). A utilização de cera para a conservação de produtos agrícolas é uma prática oriunda dos indígenas na vedação de recipientes utilizados para armazenar grãos (LIMA; NOGUEIRA, 2017). 
Figura 10. Materiais utilizados para a vedação dos recipientes que armazenam os grãos na Zona Rural (Santo Amaro e Ramada) de São Francisco, Paraíba, 2018.

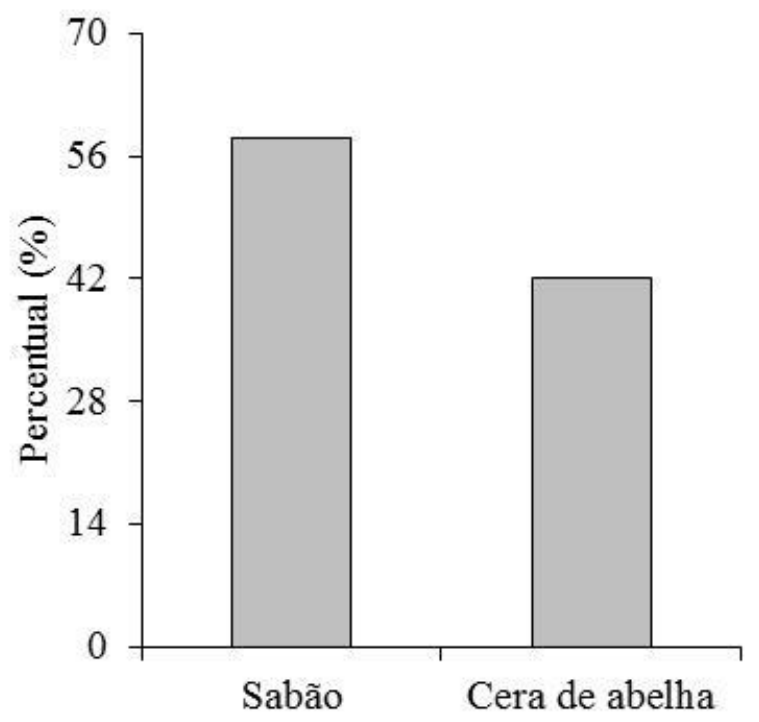

Durante o armazenamento dos grãos é observado uma série de fatores que grãos armazenados como roedores (24 dos comprometem a qualidade e a viabilidade dos entrevistados), umidade (20 produtores) e insetos entre os 6 restantes, conforme Figura 11.

Figura 11. Principais problemas observados durante o armazenamento dos grãos na Zona Rural (Santo Amaro e Ramada) de São Francisco, Paraíba, 2018.

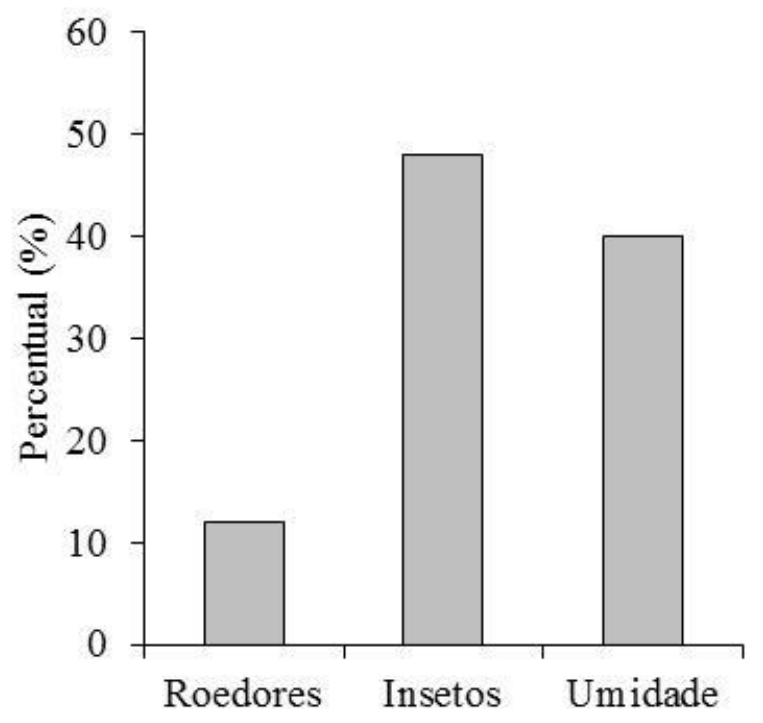

Os produtores ainda afirmaram que não possui tratamento para os grãos infectados com fungos, insetos e roedores, sendo constatada perda total uma vez infectado. Dentre os principais fatores que podem favorecer 0 surgimento de insetos na unidade armazenadora, está a umidade e esta pode ser obtida diante um processo de secagem mal feito, vedações de recipientes para armazenamento não eficientes e temperaturas não apropriadas no local de estocagem. Portanto, apenas boas práticas de armazenamento são capazes de conservar as qualidades físicas e fisiológicas dos grãos (SANTOS, 2017).

Segundo Lorini (2008), os insetos são responsáveis por grande parte destas perdas durante a pós-colheita, atingindo em muitas vezes, valores superiores a $10 \%$ dos grãos produzidos no país.

Ao indagar os produtores sobre as perdas de grãos durante o armazenamento, os mesmos relataram superioridade de $28 \%$ em perdas na armazenagem de grãos (Figura 12). 
Figura 12. Perda de grãos durante o armazenamento na Zona Rural (Santo Amaro e Ramada) de São Francisco, Paraíba, 2018.

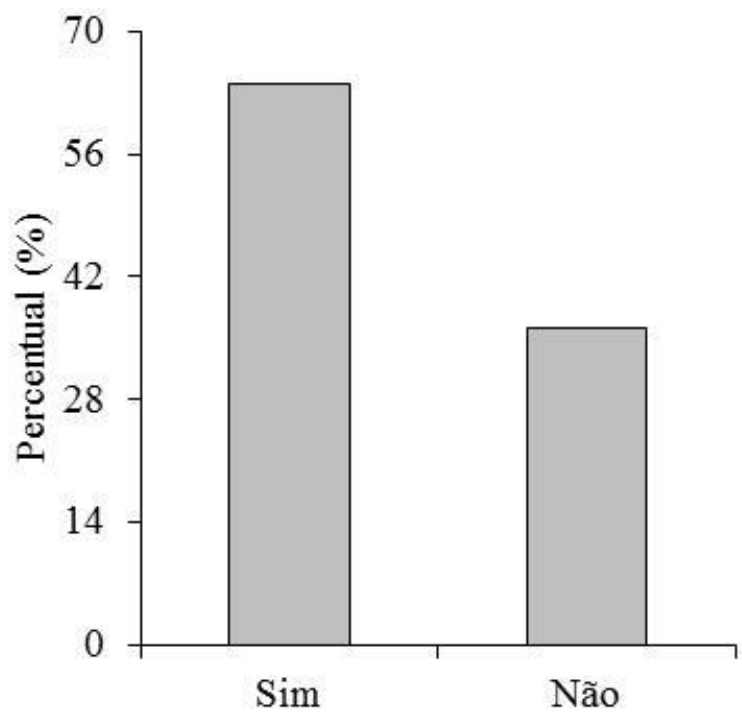

Sabe-se que o processo de armazenagem é associado a uma sequência de operações, tais como limpeza, secagem, tratamento fitossanitário, transporte, classificação, dentre outros. Após essas operações, os grãos devem obter uma série de qualidades desejáveis como baixo teor de umidade, alto peso específico, baixa degradação de componentes nutritivos, baixa susceptibilidade à quebra, baixa porcentagem de grãos danificados, alta viabilidade de sementes e ausência de pragas, fungos ou bactérias, porém, na falta de algum desses cuidados há danificação nos grãos acarretando em perdas (REGINATO et al., 2014). Diante destas informações, é possível que devido à baixa escolaridade associada a falta de assessoria técnica especializada ainda haja perdas significativas durante a estocagem dos grãos.

\section{CONCLUSÕES}

Os produtores possuem pouco conhecimento relacionado às técnicas de armazenagem, apresentando ainda perdas significativas de grãos durante o armazenamento. O método de armazenamento de grãos mais utilizado pelos produtores de São Francisco é em garrafas plásticas.

\section{REFERÊNCIAS}

ANDRADE, J.C.; GONELI, A.L.D.; HARTMANN FILHO, C.P.; AZAMBUJA, T.M.S.; BARBOZA, V.C. Quality of second-crop corn according to the period between harvest and drying. Revista Brasileira de Engenharia Agrícola e Ambiental, v.21, n.11, p.803-808, 2017. http://dx.doi.org/10.1590/18071929/agriambi.v21n11p803-808

ARAÚJO, W.L.; SOUSA JÚNIOR, J.R.; SOUSA, J.R.M.; ALEIXO, D.L.; LOPES, K.P. Diagnóstico de armazenamento de sementes em pequenas propriedades do município de Pombal-PB. Revista Verde de Agroecologia e Desenvolvimento Sustentável, v. 7, n. 3, p. 169175, 2012.

CAIXETA, F.; PINHO, E.V.R.V.; GUIMARÃES, R.M.; PEREIRA, P.H.A.R.; CATÃO, H.C.R.M. Physiological and biochemical alterations during germination and storage of habanero pepper seeds. African Journal of Agricultural Research, v.9, n.6, p.627635, 2014. DOI:10.5897/AJAR2013.7133

CAMARGO, J.S.M.; NAVAS, R. Programas institucionais de compra da agricultura familiar no município de Ribeirão Grande/SP: uma análise a partir da produção e consumo. Núcleo de Estudos, Pesquisas e Projetos de Reforma Agrária, v.20, n.35, p.230-245, 2017.

CAMPOS, T.B. A importância do instituto biológo no desenvolvimento dos estudos sobre pragas de grãos e produtos armazenados. Instituto Biológico, Centro de pesquisa e desenvolvimento de Sanidade Vegetal. São Paulo, p. 85-86, 2008.

CARVALHO, N. M.; NAKAGAWA, J. Sementes: ciência, tecnologia e produção. 5 . ed. Jaboticabal: Funep, 2012. 590p. 
CASSOL, F.D.R.; FONTES, A.M.T.; MENDONÇA, L.C.; BUTURI, C.V.; MARCON, T.R. Physiological behavior of bean's seeds and grains during storage. Anais da Academia Brasileira de Ciências, v.88, n.2, p.1069-1077, 2016. http://dx.doi.org/10.1590/0001-

\section{0}

CARDOSO, R.B.; BINOTTI, F.F.S.; CARDOSO, E. D. Potencial fisiológico de sementes de crambe em função de embalagens e armazenamento. Pesquisa Agropecuária Tropical, v.42, p.272-278, 2012.

CARVALHO, R. Manejo e a qualidade de sementes crioulas em comunidades de várzea no médio Solimões, Amazonas. 2016. 59p. Dissertação (Mestrado em Agricultura no Trópico Úmido). Instituto Nacional de Pesquisas da Amazônia, Manaus, 2016.

CONAB- Acompanhamento da Safra BrasileiraGrãos, Safra 2016/2017, Nono Levantamento. Brasília, v.4, n.9, p. 1-161, 2017.

EMBRAPA. Principais Pragas e Métodos de Controle em Sementes durante o Armazenamento. Circular Técnica, Londrina, n.73, p. 1-12, 2010.

FUJII, A.K.; RIBEIRO, J.P.; MANZOLI, R. Estudo de viabilidade econômica de um silo metálico para agricultura familiar. Revista Eletrônica Competências Digitais para Agricultura Familiar, v. 1, n. 2, p. 38-49, 2015.

GOOGLE EARTH-MAPAS. Disponível em: $<$ http://mapas.google.com>. Acesso em: 01 mar. 2018.

IBGE. Censo Demográfico 2010. Disponível em: $<$ https://www.ibge.gov.br/estatisticas-

novoportal/sociais/populacao.html.> Acesso em: 06 abr. 2018.

LEVIN, J. Estatística aplicada a ciências humanas. 2. ed. São Paulo: Harbra, 1987.

LEVINE, D.M.; BERENSON, M.L.; STEPHAN, D. Estatística: teoria e aplicações usando Microsoft Excel em português. Rio de Janeiro: LTC, 2000.

LIMA, L.N.; NOGUEIRA, E.M.S. Produção e uso dos recursos melíferos por meliponicultores da região de Cícero Dantas, BA. Gaia Scientia, v.11, n.3, p. 73-82, 2017.

LIMA JÚNIOR, A.F.; OLIVEIRA, I.P.; ROSA, S.R.A.; SILVA, A.J.S.; MORAIS, M.M. Controle de Pragas de grãos Armazenados: uso e aplicações de fosfetos. Revista Faculdade Montes Belos, v. 5, n. 4 , p. 180, 2012.

LLANO, P.M.P.; LANGE, C.; NUNES, D.P.; PASTORE, C.A.; PINTO, A.H.; CASAGRANDA, L.P. Frailty in rural older adults: development of a care algorithm. Acta Paulista de Enfermagem, v. 30, n.5, p. 520-530, 2017. http://dx.doi.org/10.1590/1982-0194201700075

LORINI, I.; KRZYANOWSKI, F.C.; FRANÇA-NETO, J.B.; HENNING, A.A.; HENNING, F.A. Manejo integrado de pragas de grãos e sementes armazenadas. Brasília, DF: Embrapa, 2015. p. 1112.

MAIA, G.B.S.; PINTO, A.R.; MARQUES, C.Y.T.; LYRA, D.D.; ROITMAN, F.B. Panorama da Armazenagem de Produtos Agrícolas no Brasil. Revista do BNDES, v.40, p.161-194, 2013.

MARCOS FILHO, J. Fisiologia de sementes e plantas cultivadas. 2. ed. Piracicaba: FEALQ, 2015. 660p.

MARREIROS, N.A.; FERREIRA, E.C.; LUCENA, C.M.; LUCENA, R.F.P. Conhecimento botânico tradicional sobre plantas medicinais no semiárido da Paraíba (Nordeste, Brasil). Revista Ouricuri, v.5, n.1, p. 110-144, 2015.

PAULINO, J.S.; GOMES, R.A. Sementes da Paixão: agroecologia e resgate da tradição. Revista de Economia e Sociologia Rural, v.53, n.3, p.517528, 2015. http://dx.doi.org/10.1590/123456781806-9479005303008

PIMENTEL, M.A.G. QUEIROZ, V.A.V.; MENDES, S.M.; COSTA, R.V.; ALBERNAZ, W.M. Recomendações de boas práticas de armazenamento de milho e soja em espiga para a agricultura familiar. Circular Técnica, Sete Lagoas, n.7, p. 1-11, 2011.

REGINATO, M.P.; ENSINAS, S.C.; RIZZATO, M.C.O.; SANTOS, M.K.K.; PRADO, A. Boas práticas de armazenagem de grãos. Anais do Encontro de Iniciação Científica, v.6, p.1-19, 2014. 
SANTOS, C.F.; SIQUEIRA, E.S.; ARAÚJO, I.T.; MAIA, Z.M.G. A agroecologia como perspectiva de sustentabilidade na agricultura familiar. Ambiente e Sociedade, v.17, n.2, p.33-52, 2014. http://dx.doi.org/10.1590/S1414-

\section{X2014000200004}

SANTOS, M.C.S. Uso de fontes alternativas de energia para secagem e conservação de grãos. 2017. 57p. Monografia (Graduação). Universidade Federal de Ouro Preto. Escola de Minas. Departamento de Engenharia de Controle e Automação e Técnicas Fundamentais, Ouro Preto, 2017.

SMANIOTTO, T.A.S.; RESENDE, O.; MARÇAL, K.A.F.; OLIVEIRA, D.E.C. DE; SIMON, G.A. Qualidade fisiológica das sementes de soja armazenadas em diferentes condições. Revista Brasileira de Engenharia Agrícola e Ambiental, v. 18, n.4, p. 446-453, 2014.

SOUSA JUNIOR, J.R.; SOUSA, J.R.M.; FURTADO, G.F.; ALVINO, F.C.G.; SILVA, H.S.; SILVA, S.S. Diagnóstico de armazenamento de grãos em pequenas propriedades do município de Pombal-
PB. Agropecuária Científica do Semiárido, v.7, n.3, p.36-40, 2011.

TEIXEIRA, C.T.M.; PIRES, M.L.L.S. Análise da Relação Entre Produção Agroecológica, Resiliência e Reprodução Social da Agricultura Familiar no Sertão do Araripe. Revista de Economia e Sociologia Rural, v.55, n.1, p.47-64, 2017. http://dx.doi.org/10.1590/1234-5678180694790550103

VERGARA, W.R.H.; OLIVEIRA, J.P.C.; BARBOSA, F.A.; YAMANARI, J.S. Análise de viabilidade econômico-financeira para aquisição de uma unidade de armazenagem de soja e milho. Gestão da Produção, Operações e Sistemas, v.12, n.1, p. 41-61, 2017. DOI: 10.15675/gepros.v12i1.1598

Recebido para publicação em 08/03/2018

Revisado em 04/04/2018

Aceito em 09/07/2018 
ANEXO

ARMAZENAMENTO DE GRÃOS EM PEQUEQUENAS PROPRIEDADES DE SÃO FRANCISCO, PARAíBA, BRASIL

1. Sexo:

I-Perfil do entrevistado

( ) Masculino ( ) Feminino

2. Faixa etária:

$\begin{array}{llll}\text { ( ) } 16 \text { a } 20 \text { anos ( ) Entre } 21 \text { a } 40 \text { anos } & \text { ( ) Entre } 41 \text { a } 60 \text { anos } & \text { ( ) Mais de } 60 \text { anos }\end{array}$

3. Escolaridade:

( ) Fundamental completo ( ) Médio completo ( ) Superior completo ( ) Sem Formação

II - Opinião do entrevistado

1. Quais os principais grãos armazenados?

( ) Feijão ( ) Milho ( ) Arroz ( ) Fava

2. Onde armazena os grãos?

( ) Garrafas plásticas ( ) Silos metálicos ( ) Tambor de plástico ( ) Outros:

3. Como é realizado a limpeza destes recipientes utilizados para o armazenamento dos grãos?

( ) Apenas água ( ) Detergente ( ) Outros:

4. Finalidade do armazenamento dos grãos?

( ) Consumo ( ) Comercialização ( ) Outros:

5. Quanto tempo os grãos permanece armazenados?
( ) Ate 6 meses
( ) Ate 1 ano
() Ate 2 anos
( ) Mais de 2 anos

6. Usa os grãos como semente também?

( ) Sim ( ) Não

7. Realiza limpeza adequada dos recipientes onde se armazena os grãos?

( ) Sim ( ) Não

8. Qual tipo de tratamento pré armazenamento é utilizado?

( ) Secagem natural: sol ( ) Secagem artificial ( ) Pulverização para eliminar insetos

9. Como é realizado a vedação destes recipientes?

( ) Sabão ( ) Cera de abelha ( ) Outros:

10. Quais os principais problemas no armazenamento dos grãos?

( ) Insetos () Roedores () Umidade

11. Perda de grão durante o armazenamento?

( ) Sim ( ) Não 